\title{
Article \\ Supply Chain Resilience Roadmaps for Major Disruptions
}

\author{
Jessica Olivares-Aguila *(D) and Alejandro Vital-Soto $\mathbb{D}$ \\ Financial and Information Management Department, Shannon School of Business, Cape Breton University, \\ Sydney, NS B1P 6L2, Canada; alejandro_vital@cbu.ca \\ * Correspondence: jessica_olivares@cbu.ca
}

check for

updates

Citation: Olivares-Aguila, J.; Vital-Soto, A. Supply Chain Resilience Roadmaps for Major Disruptions. Logistics 2021, 5, 78. https://doi.org/ $10.3390 / \operatorname{logistics} 5040078$

Academic Editor: Robert Handfield

Received: 27 August 2021

Accepted: 25 October 2021

Published: 4 November 2021

Publisher's Note: MDPI stays neutral with regard to jurisdictional claims in published maps and institutional affiliations.

Copyright: (c) 2021 by the authors. Licensee MDPI, Basel, Switzerland. This article is an open access article distributed under the terms and conditions of the Creative Commons Attribution (CC BY) license (https:// creativecommons.org/licenses/by/ $4.0 /)$.

\begin{abstract}
Background: Unexpected events or major supply chain disruptions have demonstrated the vulnerability in which supply chains operate. While supply chains are usually prepared for operational disruptions, unexpected or black swan events are widely disregarded, as there is no reliable way to forecast them. However, this kind of event could rapidly and seriously deteriorate supply chain performance, and ignoring that possibility could lead to devastating consequences. Methods: In this paper, definitions of major disruptions and the methods to cope with them are studied. Additionally, a methodology to develop supply chain resilience roadmaps is conceptualised by analysing existing literature to help plan for unexpected events. Results: The methodology is introduced to create roadmaps comprises several stages, including supply chain exploration, scenario planning, system analysis, definition of strategies, and signal monitoring. Each roadmap contains the description of a plausible future in terms of supply chain disruptions and the strategies to implement to help mitigate negative impacts. Conclusions: The creation of roadmaps calls for an anticipatory mindset from all members along the supply chain. The roadmaps development establishes the foundations for a holistic supply chain disruption preparation and analysis.
\end{abstract}

Keywords: supply chains; scenario planning; low-probability and high-impact disruptions; disruption management; disruption risk; supply chain resilience

\section{Introduction}

With the recent global pandemic and disruptions in all sectors of the economy across the world, decision- and policy-makers have experienced enormous impacts in an unforeseeable scenario. Throughout history, unexpected events demonstrated the vulnerability and lack of preparedness to face such situations. For instance, the earthquake, tsunami and nuclear crisis in Japan in 2011 caused damage estimated to be above USD 195 billion [1], and the current pandemic has shaken virtually every industry and sector. Hence, research on major supply chain (SC) disruptions is highly relevant to achieving resilience.

SCs are intricate networks that interact in different countries, infrastructures, and technological networks. Recent events have shown that SCs move the blood in these systems; paralysis in SCs leads to paralysis of the wider economy. Although they are not a critical infrastructure per se, SCs represent the backbone of economies around the world. Low-probability and high-impact events can unleash multiple crises, as their effects can snowball. Hence, research into the management of these unpredictable events is vital for both SC members and the wider society.

Unpredictable disruptions are known as black swan events. Three attributes characterise a black swan event: It is an outlier because it occurs outside the realm of regular expectations, its consequences have extreme impacts, and it is only retrospective in its predictability [2]. While a growing body of SC literature addresses disruptions and risk management, most existing papers concentrate on operational disturbances or likely disruptions. There is a tendency to ignore major uncertainties, as they are unpredictable. Additionally, traditional risk evaluation methods would not be suitable for these kinds of events, as these methods rely heavily on probabilities. 
The ongoing pandemic has characterised a major disruption with a long-term disrupted state, an unstable environment, and uncertainty about the future in the markets, supply base, and capacities [3]. Pandemic disruptions are different and unique as they developed gradually, in the long term, from multiple sources, with a spatiotemporal dynamic (moving from one region to another over time), causing disruption to supply, demand, and logistics infrastructures $[4,5]$. Hence, it is imperative to call for continuous preparedness for disruptions, living in anticipation of them, and learning how to manage SCs in times of crisis [6].

The SC context sorely needs a detailed analysis of this kind of extraordinary disruption. The scale and scope of the pandemic called for a new frontier in SC risk management (SCRM). SCRM frameworks have five major components: risk identification, risk assessment, risk consequences, risk management response, and risk performance outcomes [7]. However, SCRM is not enough to deal with unexpected events, as it focuses on identifying possible disruptions, mapping their most likely effects, and developing preventive and mitigation plans to reduce risk exposure.

This paper does not purport to provide solutions for unpredictable disruptions; instead, it offers a methodology that enables the unveiling of plausible futures and how to react to them. The contribution of this paper is twofold-the study of definitions of unexpected events in the SC context and the introduction of supply chain resilience roadmaps for major disruptions. This paper answers the following research questions:

- What are the different definitions of unexpected events?

- How have unexpected events been approached in SC?

- What methodologies are appropriate to cope with unexpected events?

\section{What Are Unexpected Events in Supply Chains?}

SCs are characterised by an increasing number of interactions among all the parties involved in delivering customer requirements. Although unexpected events have a low likelihood, globalisation has amplified the breadth, length, and complexity of SCs, which exposes them to an ever-larger number of unforeseen events [8]. While operational disruptions have been widely analysed in the SCRM domain, unpredictable disruptions with low probability and high impact have received little attention. For that reason, it is imperative to plan for and adjust to their occurrence to the greatest extent possible, rather than continuing to try to predict or simply ignore them.

The literature on SC disruption grew exponentially from 2012 to 2019, which is attributable to the many disruptions observed in SCs after the tsunami in Japan and flooding in Thailand, both of which occurred in 2011 [9]. Due to the ongoing COVID-19 pandemic, the SC disruption field is showing a more significant upheaval trend. However, it is crucial to determine which methodologies are applicable for operational disruptions and which for unpredictable disruptions.

Resilience has been studied through the lenses of redundancy and flexibility. While SC managers are more inclined towards flexibility because they can also observe improvement at the operational level [10], flexibility is not enough for major disruptions. In order to achieve a higher degree of resilience, the twin goals of reconfigurability [11] and viability [12] are encouraged.

Unpredictable events are known by different names in the literature: black swan events, disasters, unexpected events, macro-risks, unpredictable disruption, low-probability and high-impact events, SC tsunamis, catastrophes, emergencies, uncertainties, dragon kings, perfect storms, mega-disasters, mega-crises, emerging risks, disruption risks, super disruptions, deep disruptions, and so on. The sheer variety of terms reveals the different perspectives from which these situations are studied.

Definitions of some of these terms for disruptions are presented in Table 1. As observed from Table 1, a common language or taxonomy to define unexpected major disruption has clearly not yet been established. Different authors have proposed their definitions and 
terms. Although all the terms describe events that have profound impacts, the level of predictability of such events is not always well defined.

Table 1. Definitions of terms for describing disruptions.

\begin{tabular}{|c|c|c|}
\hline Term & Author & Definition \\
\hline Disruptions & {$[13,14]$} & $\begin{array}{l}\text { Unplanned and unanticipated events that disrupt } \\
\text { the normal flow of goods and materials within } \\
\text { an SC. }\end{array}$ \\
\hline Disruption risks & [15] & $\begin{array}{l}\text { Major disruptions caused by incidents such as } \\
\text { natural and human-made disasters. }\end{array}$ \\
\hline Black swans & [2] & $\begin{array}{l}\text { Rare events that cause extreme impacts and are } \\
\text { predictable only in retrospect. }\end{array}$ \\
\hline Dragon kings & [16] & $\begin{array}{c}\text { Meaningful outliers that are found to coexist with } \\
\text { power laws in the distributions of event sizes } \\
\text { under a broad range of conditions in a wide } \\
\text { variety of systems. }\end{array}$ \\
\hline Perfect storms & [17] & $\begin{array}{l}\text { Involve mostly aleatory uncertainties } \\
\text { (randomness) in conjunctions of rare but } \\
\text { known events. }\end{array}$ \\
\hline Deep uncertain events & [18] & $\begin{array}{l}\text { Isolated, non-repetitive, extreme events for which } \\
\text { the likelihood of occurrence cannot be evaluated. }\end{array}$ \\
\hline Black swans & [19] & $\begin{array}{l}\text { Rare events with extreme consequences, or } \\
\text { extreme, surprising events relative to present } \\
\text { knowledge and beliefs (unknown unknowns, } \\
\text { unknown knowns, and events with negligible } \\
\text { probability). }\end{array}$ \\
\hline Tsunamis & [20] & $\begin{array}{l}\text { Rarely occurring SC phenomenon with a sudden } \\
\text { and devastating impact on a focal firm, its supply } \\
\text { network, or even the entire industry. }\end{array}$ \\
\hline
\end{tabular}

In order to observe how these terms are related, we conducted a search in SCOPUS using the following keywords: 'black swan event' AND 'supply,' 'black swan event' AND 'management,' 'unpredictable disruption' AND 'supply,' 'low-probability and high-impact' AND 'supply management,' 'tsunamis' AND 'supply management', and 'disruption risk' AND 'supply management'. The search generated 1363 documents. After reviewing the results, we observed that our search had included operational and likely disruptions. As the scope of the present paper is unpredictable disruptions, the keywords were narrowed. The search was restricted to 'Engineering,' 'Business and Management,' 'Decision Sciences', and 'Computer Sciences,' yielding 318 documents, including journal articles and conference papers.

The literature was subsequently analysed using VOSviewer (www.vosviewer.com, accessed on 14 February 2021). Keyword co-occurrence analysis was implemented, as shown in Figure 1. The circle size represents the weight of each keyword, its relatedness strength is represented by the proximity of their position in the network, and the strength of the links is represented by the thickness of the lines [21]. 


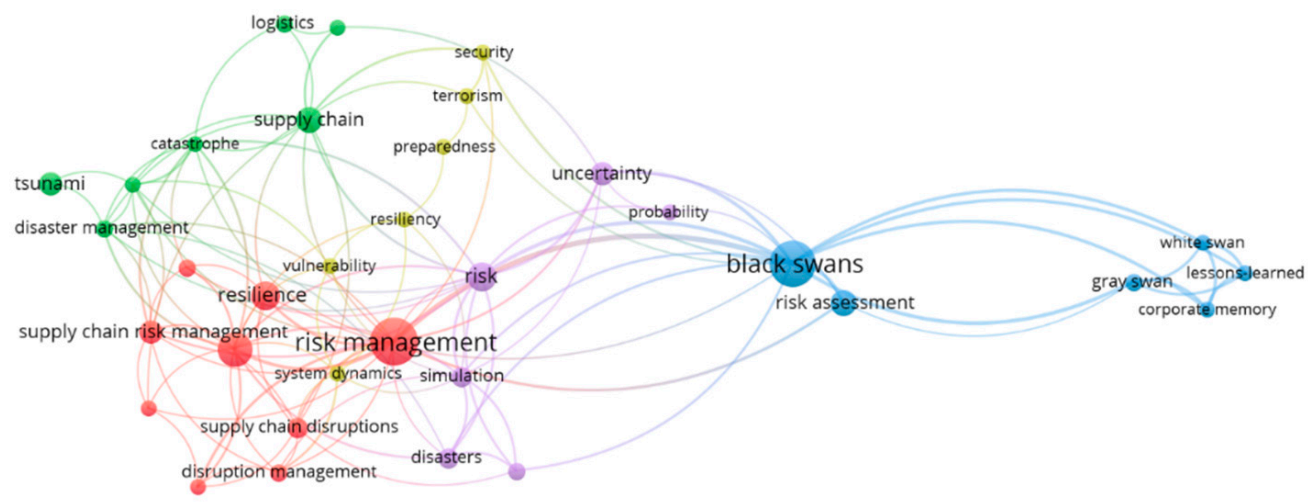

Figure 1. Co-occurrence network of keywords about major disruptions.

As Figure 1 shows, 'risk management' and 'black swans' are the terms with the most significant weight and strongest link, although neither term is very close to 'supply chain'. Given the variety of terms in the literature that define unpredictable disruptions, it is not surprising to find such a scattered network.

Black swan events have been described as unknown unknowns [2]. Aven [22] suggests that black swan events can be 'unknown unknowns,' 'unknown knowns', or 'known but not believed to occur because of low judged probability'. He categorised a new type of virus as an unthinkable or black swan event. He mentioned that in a situation with large uncertainties and a lack of prediction models, methods that call for anticipatory thinking such as scenario generation are required, as scenarios may offer useful insights into what could happen and reveal possible black swans.

Sheffi [8] noted that, even though black swans cannot be pinpointed, their nesting spots in the global economy can be considered enabling organisations to think about obvious and less obvious risks. Hence, it is imperative to characterise plausible settings for unpredictable disruptions.

\section{How have Unexpected Events Been Approached in SCs?}

The last decade has seen an emphasis on resilience in the SC context. There is a wealth of literature on SCRM and how to boost resilience in SCs. Several works have proposed quantitative methods for managing disruption risk and resilience. Most of these quantitative methods are not included in the present study because they deal with disruptions that can somehow be predicted and use probabilistic approaches. For a detailed literature review of quantitative methods on disruptions and recovery considerations, see Ivanov, Dolgui [23].

This section focuses on methods that are intended for unexpected events. Studies in this area can be broadly divided into those that focus on planning and preparation and those that focus on recovery. A number of remarkable frameworks have been published in the literature to prepare for uncertainties and build resilience. For instance, Christopher and Peck [24] proposed a framework to create a resilient SC, which includes SC (re)engineering, SC collaboration, agility, and the SCRM culture. Kleindorfer and Saads [14] developed a conceptual framework that incorporates risk assessment and mitigation and calls for a specification of risk sources, which may be difficult to define when dealing with an unexpected event. Furthermore, the risk assessment proposed by Kleindorfer and Saads is based on probabilities or worst-case scenarios.

Craighead and Blackhurst [13] proposed a theoretical framework that integrates SC network design characteristics and SC mitigation capabilities to assess, prevent, and mitigate the severity of an SC disruption, while Knemeyer et al. [25] suggested a process that builds on an existing risk analysis framework by incorporating a methodology used by the insurance industry. The drawback of that framework is that it uses probabilities that may not be calculable, and even if those probabilities can be computed with some confidence, the possible event would be disregarded because of its very low probability. 
Sodhi and Tang [26] proposed a 3-D framework (detect, design, and deploy) that focuses on time and response processes instead of impact, probabilities, or cost. It is intended to be used in planning procedures before an event occurs. Pettit and Fiksel [27] presented an SC resilience framework that balances capabilities and vulnerabilities to create a competitive advantage; it helps provide insights into strengths, weaknesses, and priorities.

Klibi and Martel [18] developed a three-phase hazard modelling approach, including SC hazard characterisation, vulnerability sources and exposure levels, characterisation of the disruption, and an assessment of consequences. Based on that model, they implemented a Monte Carlo approach to generate plausible future scenarios for hazards. As the modelling is based on available information and experience, it might completely disregard certain potential extreme events for which no information and experience exist.

Blackhurst et al. [28] published an empirical framework of supply resilience which considered resilience enhancers (human capital resources, organisational and physical capital resources) and reducers (flow of activities and units and sources of flow units). A system dynamics framework to analyse different risks with specified probabilities was presented in [29]. That framework included risk identification via historical data and probabilities, risk assessment and risk mitigation. Bradley [30] proposed a risk measurement and prioritisation method to account for rare risks. The method incorporated failure modes and effects analysis (FMEA) into SCRM for risk prioritisation purposes.

Simchi-Levi et al. [31] developed a methodology in which SC mapping and stress testing are combined to unveil critical SC entities and design strategic, tactical and operational decisions. They use the risk-exposure index, time-to-recovery, and time-to-survive to design a robust SC. Thekdi and Santos [32] proposed a performance metric to characterise resilience in interdependency modelling and integrated scenario-based methods to measure economic sensitivity to sudden-onset disruptions (i.e., terrorist attack, labour strike, and hurricane). Pavlov et al. [33] presented a genome representation aiming to disrupt scenario recognition and optimise SC reconfiguration paths. The disruption scenarios are linked to different risk aversions and the resulting policies in the SC. Ivanov and Dolgui [34] introduced a low-certainty-need SC framework in which SC behaviour depends less on the certain knowledge of the environment and changes in that environment. They proposed a combination of lean and resilient elements such as structural variety and simplification, process and resource utilisation flexibility, and efficient parametric redundancy. Adobor [35] described a multi-level SC resilience framework that emerges as a combination of individual, organisational, and inter-organisational resilience, which work together to identify significant sources of SC risks.

In order to tackle the uncertain SC environment, simulation modelling is an appealing approach to analysing unexpected events. Olivares-Aguila and ElMaraghy [36] proposed a system dynamic framework to holistically analyse the impact of major SC disruptions. Different hypothetical disruption scenarios were implemented to observe system behaviour. They urged planning for disruptions in order to lay down proactive and reactive strategies from the planning and design phases to minimise impacts on the SC.

Several research efforts have focused on analysing how to react to and mitigate disruptions once they have occurred. For instance, Schätter et al. [37] proposed a decision support system that integrates scenario techniques, optimisation models and approaches from decision theory as a tool against disruptions. They simulated a scenario in which a retail food company is affected by a pandemic disaster. Ivanov [38] presented a simulation model to predict the impacts of COVID-19; sensitivity scenarios were developed to define operative and long-term effects.

As SCs have evolved from simple, linear arrangements to highly complex, interconnected networks, dealing with disruptions using the network theory approach has attracted interest. An overview of the methods used to mitigate SC disruptions was presented by Bier, Lange, and Glock [39]. They emphasised that most of the proposed studies addressed risk and structure separately, with only a few focusing on their intersection (e.g., [40]). 
While the SC structure plays an important role, the network dynamics could be challenging to characterise.

Conceptual frameworks that call for identifying threats or the introduction of redundancy or flexibility have been proposed, as summarised in the paragraphs above. However, to develop SC resilience, analysis of unexpected events should be carried out in advance. Hence, in the next section, methods to deal with unforeseen events are presented.

\section{What Strategic Methods Could Cope with Unexpected Events?}

Aven [41] noted that traditional risk analysis perspectives could not be used to meet black swan risks because those methods tend to be static. Moreover, probability risk assessment treats risk and uncertainties based on assumptions that could conceal critical issues and therefore provides a misleading account of the possible occurrence of future events. Traditional risk assessment methods address the issue of what can happen. However, when dealing with 'unknown unknowns', anticipatory methods should be considered. Examples of practices for identifying black swan events are anticipatory failure determination (AFD) and red teaming.

AFD looks at how to make a failure occur instead of retrospectively looking at how that failure happened. It is suitable for revealing and developing failure scenarios. AFD is also called the theory of scenario structuring, and it is better than other risk assessment methods because it provides a systematic process for inventing failure events and scenarios [42]. Scenario analysis using AFD could offer insights into future unexpected events and a description of the situations that would enable them to occur.

Red teaming, another approach to exploring unexpected events, is a devil's advocate methodology. It identifies and reduces risk by offering alternative interpretations and challenging established thinking [43]. It helps organisations to improve themselves by providing outsider perspectives.

For strategic thinking, scenario planning emerged in the aftermath of World War II as a method of military planning. It was imported into social forecasting and public policy by Herman Kahn. Pierre Wack of Royal Dutch/Shell introduced the scenario approach as strategic planning in the industrial field during the 1970s [44]. Wack [45] defined scenario planning as a discipline for rediscovering the original entrepreneurial power of creative foresight in the context of accelerated change, greater complexity, and genuine uncertainty. Scenario planning captures the richness and range of possibilities to consider otherwise ignored changes [46].

Scenarios are descriptions of plausible events that may happen in the future and result in a particular set of outcomes. They are defined based on assumptions such as drive forces, relationships and interconnections [47]. The scenario activity is essentially iterative, and scenarios play the important role of raising questions. Rather than guess what will happen exactly, scenario planning is methodical thinking about the unthinkable [48]. It is a useful strategic tool to gain a competitive advantage in business contexts. For instance, Sodhi [49] proposed scenario planning to formulate strategies to increase shareholder value and then refine those strategies with optimisation models.

The role of scenario planning is to help managers recognise, consider, and reflect on the uncertainties; it should serve as a powerful tool to increase awareness and understanding of how different conditions will develop along different paths and anticipate them. Scenarios are the best language for a strategic conversation, as they allow for differentiation in views combined with a shared understanding of the situation [48]. The goal of scenario planning is not to develop a specific solution but to engage decision-makers in meaningful dialogue to understand critical issues for the organisation's future and broaden perception about situations that could erupt [50].

Several researchers have noted the need for stress testing [6,51]. Stress tests seek to reveal whether a system can withstand a shock; they are typically static, with parameters and models determined before testing begins. However, stress testing would fall short in the area of interest of the present study, as unexpected events evolve in increasingly rapid 
and unpredictable ways [52]. Hence, dynamic stress test or scenario planning is imperative to tackle unforeseen events at the level of strategic decision-making.

Although scenario planning is not new, it has not been fully exploited in the SC resilience domain, especially for unexpected events. The lack of a descriptive methodology for implementation for major disruptions might be one reason. However, some proactive industries have implemented the scenario planning approach. For instance, Cisco Systems has developed 'playbooks,' 14 pre-planned SC incident management scenarios used to conduct drills that simulate disruption events [53]. Strong et al. [47] presented a framework to develop scenarios for disaster risk reduction. While that framework is intended for stakeholders of the disaster risk management community, it provides insights into the use of scenario planning for the private sector and SCs.

\section{Research Gap}

Researchers have discussed SC resilience from different perspectives and presented diverse frameworks that focus mainly on identifying threats or introducing redundancy or flexibility, as observed in Section 3. Moreover, methods that call for anticipatory thinking to make strategic decisions were discussed in Section 4. Although methods in Section 4 could provide insights for SC resilience against unexpected events, they have received little attention in SC disruption management. Thus, this study bridges this gap and proposes creating supply chain resilience roadmaps as a holistic method that considers developing and evaluating scenarios to prepare for unexpected events. The creation and preparation of different scenarios would allow decision-makers to rehearse and practice for unforeseen circumstances, as described in the next section.

\section{Supply Chain Resilience Roadmaps}

In order to prepare for unexpected events, a mindset of awareness and preparedness is essential. Risk management on its own is not enough because it is based on past events. Hence, thinking forward is needed to analyse the system and identify blind spots that could unleash an unexpected event. The proposed methodology for developing supply chain resilience roadmaps, as shown in Figure 2, is intended to be used at the strategic decision-making level because we are dealing with major disruptions. It features several stages: SC exploration, scenario development, system analysis, the definition of strategies, roadmap development, and signal monitoring considerations. The methodology begins with SC exploration, which is continuously updated according to signals received from the SC environment; it is not a step-by-step process but an iterative one. Each stage is defined in the subsections below.

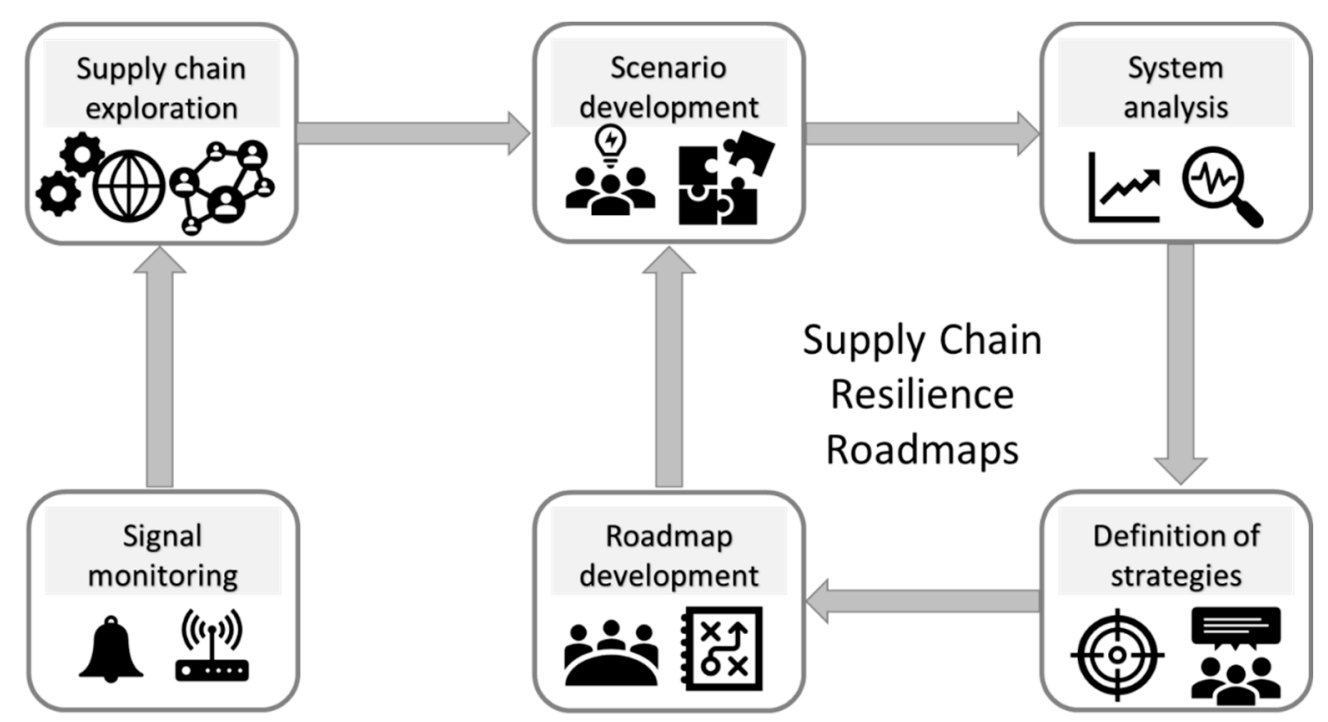

Figure 2. Methodology for developing supply chain resilience roadmaps. 
The roadmaps are not designed to describe future events accurately but to identify forces that could push the future in different directions. They are intended to be creative, iterative, and interactive. Depending on the SC and industry that is being analysed, adaptations need to be performed.

\subsection{Supply Chain Exploration}

The first stage of analysis is defining the SC and the environment in which it operates. The exploration should include SC mapping, which captures the environment's essence and allows the representation of the current SC state [54]. Each organisation will need to define the critical dimensions and characteristics to consider. Golan et al. [54] highlighted that SC mapping should include upstream mapping (suppliers and sub-suppliers), downstream mapping (customers), and midstream (processes to convert the raw material to a value-added product) mapping. A list of starting questions to map the SC is presented in Table 2. Although questions may need to be added, changed, or deleted depending on the sector, SC structures, dynamics, and logistics features need to be considered. Importantly, considerations regarding interactions of the various SC components such as spatial, enterprise, value, supply-demand, time, and products need to be addressed $[55,56]$.

Table 2. Basic questions for developing SC mapping.

\begin{tabular}{|c|c|}
\hline Domain & Questions \\
\hline Relationships & $\begin{array}{l}\text {-Who are the tier- } 1 \text { suppliers, tier- } 2 \text { suppliers, tier- } 3 \text { suppliers, distribution centres, and markets? } \\
\text {-Who are the critical supply entities? } \\
\text {-What are the sourcing strategies (single or multiple suppliers) and dynamics? }\end{array}$ \\
\hline Location & -Where are the SC entities (suppliers, plants, distribution centres) located? \\
\hline Organisational Structure & -Is the assignment of authority centralised or decentralised? \\
\hline Information structure & $\begin{array}{l}\text {-How does information flow in the SC network? } \\
\text {-Is there a real-time information update? }\end{array}$ \\
\hline Competition & -Do our competitors have the same suppliers? \\
\hline Customers & $\begin{array}{l}\text {-Are our customers loyal and willing to wait for our products? } \\
\text {-Where are the customers located? }\end{array}$ \\
\hline Demand & $\begin{array}{l}\text {-What is the demand pattern for each good category? } \\
\text {-What is the demand planning process? }\end{array}$ \\
\hline Inventory & $\begin{array}{l}\text {-What are the inventory policies? } \\
\text {-What are the replenishment lead times? }\end{array}$ \\
\hline Products & $\begin{array}{l}\text {-Are our products basic products rather than innovative products? } \\
\text {-What products / components/raw materials are the most critical? } \\
\text {-What products provide most of the company profit? }\end{array}$ \\
\hline Product structure & $\begin{array}{l}\text {-Are our products integral or modular? } \\
\text {-Are there alternative or substitute components/parts/products? }\end{array}$ \\
\hline Process structure & $\begin{array}{l}\text {-What is the manufacturing process? } \\
\text {-Where the factories are located, and what is their capacity? } \\
\text {-What is the processing time for each product type? } \\
\text {-Is there supply capacity scalability? }\end{array}$ \\
\hline Process flexibility & $\begin{array}{l}\text {-Are there other plants capable of producing the same products? } \\
\text {-Are there alternative process plans? }\end{array}$ \\
\hline Process reconfigurability & $\begin{array}{l}\text {-Are there other plants capable of being retooled quickly to produce the same products? } \\
\text {-Is it possible to repurpose machines/equipment? }\end{array}$ \\
\hline Transportation & $\begin{array}{l}\text {-What routes are used in the SC? } \\
\text {-What are the required transportation modes to move goods among the SC entities? } \\
\text {-What is the transportation capacity per transportation mode? } \\
\text {-Is there delivery capacity scalability? } \\
\text {-What shipment policies are implemented for each good category? }\end{array}$ \\
\hline
\end{tabular}


The SC mapping is developed to know which role each SC entity is playing and how they all interact in the system. It is essential to be aware of policies, key drivers, forces, and priorities. The SC mapping process is a substantial task that is required to obtain an understanding of the objectives and operations in everyday settings.

At this stage, the formation of a cross-disciplinary team is needed to provide diverse perspectives. The team will embark on the development of scenarios. As the whole process is strategic in nature, strong top-management support is vital to keeping the team engaged.

SC mappings have been widely supported by researchers and implemented in the industry. For instance, in the automotive industry, an SC mapping methodology was proposed in [57]. Similarly, a methodology to map Ford's supply chain has been introduced in [58]. As highlighted in [59], SC mapping can improve visualisation and monitoring and improve supply chain's resilience. Therefore, the supply chain exploration throughout supply chain mapping is justifiable.

\subsection{Scenario Development}

The scenarios are used to reveal plausible futures. The definition of a scenario is an activity that evolves. However, the scope (number of scenarios) and detail (the features considered) should be established at the beginning of this stage. Scenarios need to be comprehensive, consistent and coherent [60]. They should describe a rational route that makes processes and decisions explicit and consistent [47].

The scenario development stage is one of the most complex; it requires the participation of the cross-disciplinary team and includes several steps before the scenarios to be analysed are defined. The steps for scenario definition are described in Sections 5.2.1-5.2.3. It is worth noting that the scenario definition task should be updated and performed at least once a year because SCs are dynamic, and we are targeting strategic and tactical decisions.

\subsubsection{Scope and Objectives}

Scenarios are used when there is not enough available information about future events. However, there is a possibility that an event with high impact could emerge. For that reason, scenario planning will target decisions from the tactical through the strategic levels. Hence, the time horizon to consider in scenarios where disruption occurs should last at least one quarter and as much as several years.

At this stage, as we are dealing with unexpected events, it is crucial to define what type of risks are not going to be analysed (e.g., operational disruptions). Moreover, a scope definition in terms of products, markets, geographical areas and technologies should be considered. Other features that could be included in the scope step are the speed of the propagation of the event and the speed of propagation of any ripple effects.

Once the scope is set, the SC exploration stage can be used to identify the relevant objectives to pursue and how can they be evaluated.

\subsubsection{Collection of Information}

In this stage, the role of data is a crucial factor to define and support scenario planning. In the light of the availability of more data (big data) and the incorporation of new methodologies such as machine learning, the implementation of data analytics can be used to gather historical data about disruption risks and operational risks and extract information from large and diverse datasets [61,62]. Internal data (e.g., enterprise resource planning data), consumer data (e.g., point-of-sale data), socioeconomic information (e.g., gross domestic product, inflation rates), and external data (e.g., climate change) can be collected to map risky factors and locations. Information regarding key performance indicators and key performance predictors will be used to define parameters and variables in the scenarios. 


\subsubsection{Developing Scenarios}

Brainstorming and red teaming can help to articulate scenarios. Brainstorming can be used as a starting point to characterise plausible unforeseeable events; however, this could result in an overly challenging task. Hence, internally in the cross-disciplinary team, the AFD approach can be used to discover possible unexpected events not by looking for a reason but by concentrating on how to make the SC fail. For internal SC fails, the list below shows some possible ways to make an SC fail; it can be used as a starting point to develop scenarios.

- $\quad$ Lack of money;

- Lack of employees;

- Lack of production;

- $\quad$ Lack of material;

- Lack of supply;

- $\quad$ Lack of demand;

- Lack of transportation;

- Lack of information;

- Lack of communication.

For external driving forces, social, technological, economic, environmental, and political (STEEP) driving forces can be considered [63]. In order to avoid institutional myopia, red teaming is encouraged to include external perspectives. However, caution is needed to prevent overly complicated scenarios. Hence, individual concerns or risks need to be consolidated into driving force categories [50].

The scenarios can be developed as creative narratives or storylines that reflect future situations. Alternatively, a scenario matrix that plots two plausible issues creating a plane with four quadrants could help define a combination of driving forces. Each quadrant could help develop narratives for that quadrant. Although the matrix approach is the most common, the goal is to develop provocative storylines around significant risks and driving forces [50].

Creating a pool of disruption scenarios at this stage is worthwhile, although not every scenario will be analysed because that would not be feasible [64]. Hence, scenarios should have the following characteristics: (1) comprehensiveness with respect to scope, (2) agility in containing modular components that allow for adaptability and scalability of the scenario, (3) distinction from other scenarios, (4) plausibility, and (5) coherence. It is crucial to define a small number of scenarios to analyse.

Researchers and organisations have supported the development of scenarios when dealing with macro-catastrophe threats such as disease outbreaks, climatic catastrophes, and technological catastrophes [65]. Global companies have paid more attention to the development of scenarios. For instance, a technology corporation with manufacturing and service SCs prepared, in 2019, a volcano explosion scenario and developed recovery plans. Those prepared recovery plans helped them during the coronavirus outbreak in 2020 [66]. Similarly, at the first outbreak of COVID-19, Johnson \& Johnson developed several scenarios that allow the company to plan ahead instead of being forced to react in an emergency [67]. As observed from the examples, the definition of scenarios has been critical to overcoming unexpected situations. Therefore, the development of scenarios is included in the roadmap methodology.

Sheffi [68] proposed categorising disruptions based on the following three dimensions: disruption probability, consequences, and detection lead time. He notes that detection lead time for an event could range from positive through zero to negative. An event with a positive detection lead time can be forecast or detected in advance. Zero detection lead time means that the event is only detected when it happens, and negative detection lead time refers to a disruption that is not detected until after the event occurs.

Since it is not possible to evaluate countless scenarios, scenario categorisation can be performed by evaluating each scenario based on two criteria: impacts and levels of detectability. For instance, Figure 3 shows four scenarios (S1 through S4) scattered on the 
superior and inferior planes; however, scenarios that are located on the bottom right (S4) are the ones that should be analysed.

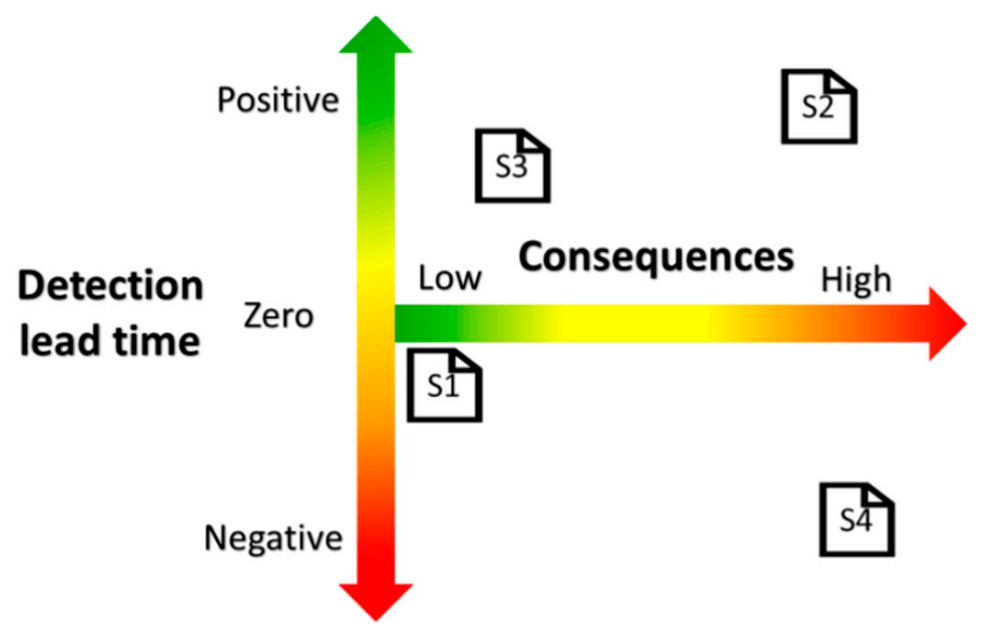

Figure 3. Categorisation of scenarios.

\subsection{Scenario Analysis}

Once the scenarios are defined, they need to be examined. Depending on the organisation, different approaches could be used. However, consideration of dependencies and interconnectivity among the SC network and the environment needs to be carried out. It would be useful to have performance metrics and a safe environment to visualise the impacts and evolution of each scenario. It is also relevant to consider the possible adaptation of the SC network structure.

Different research methodologies can be used to analyse the systems when facing major disruptions, such as mathematical optimisation, simulations, and control theory [69]. Depending on the granularity of the system analysis, these methodologies can be developed to observe the possible impacts of the different scenarios at the network, process, and control level [54].

Simulation models allow the representation of complex settings and test scenarios in a risk-free environment. The models allow the creation of various scenarios, the observation of the impacts on key performance indicators, and the discovery of key performance predictors [38]. Different simulation paradigms such as discrete-event simulation, agentbased simulation, and systems dynamics have been used to develop scenarios when facing major disruptions [70-72]. For instance, system dynamics applies system thinking and modelling to complex systems [73]. Hence, the behaviour of the whole system is recognised.

System dynamics can be very useful as it focuses on the analysis of the behaviour of the whole system rather than a point-by-point match with the existing system. The simulation model could consider the SC's possible reconfigurations to observe the structural and dynamic changes of the disruption and recovery. For example, the system dynamics framework proposed by Olivares-Aguila and ElMaraghy [36] to model SC disruptions could be modified to suit specific scenarios that include SC network reconfigurations. Effects on key performance indicators over time must be analysed to observe the system behaviour and to identify macro-level dependencies. Likewise, Zhu and Krikke [74] proposed a system dynamics simulation to analyse different scenarios and propose policies to manage a perishable supply chain after the COVID-19 outbreak. Zhu et al. [75] also observed the impacts of SC integration strategies on disruption recovery using a system dynamics approach, which allowed them to recommend operational integration as the best practice for disruptions such as capacity and demand disruptions.

Scenario-based system dynamics can deliver prediction results and sensitivity analysis results that can be used to delineate policies and recommendations [76]. Hence, organisations should possess a model-based scenario design and simulation, which allow them to 
observe the disruptions and their propagation mechanism [55]. The integration of simulation and optimisation can also be implemented to develop predictive disruption simulation and optimise the recovery policies accordingly [62]. Simulation-optimisation methods are specially designed to handle uncertainty, time-efficiency, and optimisation of suitable criteria [77].

As pointed out by Johnson \& Johnson, mathematical models and simulations have allowed the company and supply chain leaders to understand what they could withstand and what would be required to adapt [67]. Regardless of the methodology to be employed for the system analysis, the development of the model is a task that requires considerable efforts to build a representative model at the right abstraction level to try the disruptions in a risk-free world.

\subsection{Definition of Strategies}

Once the system analysis has been completed, different proactive and reactive strategies need to be considered. In order to define such strategies, risk attitudes should be assessed, as different risk attitudes may lead to different solutions [78]. For instance, a risk-seeking attitude could lead to a reactive or 'do-nothing' strategy. On the contrary, a riskaverse organisation would prefer a proactive strategy. Hence, the whole SC organisation should agree on the desired level of resilience.

Proactive strategies such as structural variety, flexibility, redundancy, segmentation, agility, and increased visibility can all be considered $[3,15,34]$. However, in order to maintain SC viability when facing a major disruption such as a pandemic, Ivanov [56] proposed four major adapting strategies-repurposing (process flexibility), substitution (structural reconfiguration), scalability (capacity), and intertwining (collaboration) — that have emerged in different sectors to mitigate the disruption impacts.

A critical point to frame the strategies is the level of intellectual property willing to be shared between organisations within the SC. Companies agreeing to work together to maintain business continuity and share intellectual property could consider substitution for components and materials. Moreover, collaboration could help organisations adapt and pivot to a new business with a very short ramp-up process, should that become necessary. Considerations of products redesign or SC configuration to mitigate or even prevent disruptions could help reduce exposure to vulnerability [79]. In addition, the evaluation of a postponement strategy as a mitigation technique can be considered. For instance, He and Alavifard [80] presented a model for assessing the value of postponement in mitigating demand and supply disruption by considering the value of managerial flexibility.

The team defining the proposed strategies also need to consider the time to adopt the selected strategies and the required resources. As mentioned in the previous stage, using a simulation model will be beneficial. In this stage, the simulation model would enable observing the 'implementation' of the strategies in a risk-free environment. Different recovery strategies can be analysed to select those that best suit the objectives. Sensitivity analysis can be conducted for the simulated scenarios to obtain the ranges in which the scenario and proposed strategies would be feasible and valid [38,76].

Access to different scenario analysis tools has allowed organisations to sense what the future may look like and develop mitigation plans to deal with unexpected events [81]. For instance, Global and regional AGGO's company teams analysed scenarios to define strategies in a region and predict possible impacts [82]. As a result, they could implement strategies to continue producing during the pandemic. Similarly, Rockwell Automation has developed playbooks that define actions and measures to take in time of disruptions. When COVID-19 started, the playbooks planned by Rockwell Automation allowed them to follow the pre-defined processes to deal with the situation efficiently [83].

\subsection{Roadmap Development}

Documentation regarding the scenarios and the mitigation plans have been carried out in different industries (e.g., Cisco [53] and Rockwell Automation [83]) to outline 
procedures to follow when the scenario becomes a reality. Therefore, in this methodology, the documentation of roadmaps is a critical task.

The roadmaps will help organise the flow of actions should a significant disruption happen. A roadmap contains a set of directions to follow according to drills performed throughout the 'what-if' scenarios developed during the previous stage. The distribution of roadmaps among stakeholders is critical because all key decision-makers need to understand how the strategies in each roadmap are to be adapted.

At this stage, roadmaps that outline and document each scenario need to be compiled. Each roadmap should contain complete documentation regarding the roadmap preparation, roadmap implementation, and roadmap debriefing.

The roadmap preparation section should include documentation pertaining to (1) the scenario settings considering the major disruption and propagation possibilities; (2) a description of the possible impacts and outcomes; (3) a list of key performance metrics and predictors to monitor before, during, and after disruption; (4) documentation regarding the developed model and its assumptions to test what-if scenarios; and (5) a sensitivity analysis showing the ranges for key variables.

The roadmap implementation section should describe (1) a set of policies and strategies to implement, (2) actions and processes to perform for each strategy, (3) expected results and milestones from the actions, (4) alternative mitigation protocols, (5) designated authorities to execute the actions and their roles, and (6) a list of critical internal and external contacts responsible for actions.

Finally, the roadmap debriefing section should contain (1) a definition of the implemented strategies; (2) a description of advantages and shortcomings of the executed plans; (3) a summary of lessons learnt from the scenario implementation; (4) a list of opportunities created during the disruption, if any; and (5) documentation about reviews and updates.

It is relevant to consider that depending on the organisation, additional requirements, guidelines, and policies need to be included or removed in the definition of the roadmaps.

\subsection{Signal Monitoring}

Situational awareness is needed to keep the roadmaps updated. Trends in internal and external data that show changing environments must be monitored and evaluated to modify the scenarios' settings and the impact on existing roadmaps. A scanning library needs to be created to collect and store signals employed to examine, update scenarios, and identify when disruption is starting to occur [84].

With the rapid increase in technological developments in recent years, growing attention has been paid to the development of digital twins for managing disruption risk. A digital SC twin is a model which represents the network state for complete SC visibility to improve resilience and test contingency plans [61]. Digital twins (DTs) will gather information from the environment, process it, and simulate responses. DTs will enable visibility among SC entities, business transparency, and integration. They should be designed to facilitate connectivity, interoperability and traceability for data exchange. Hence, DTs constitute a new data-driven vision, which combines simulation, optimisation, and data analytics, to allow predictive and prescriptive analytics and improve resiliency and test contingency plans [62]. They will be like nervous systems that respond to stimuli from the external environment and to internal conditions.

Ivanov and Dolgui [61] developed a generic structure of a digital SC twin to manage disruption risks. Burgos and Ivanov [85] highlighted the importance of SC digital twins to enhance end-to-end visibility, which can provide the basis for proactive and resilient SC designs. Similarly, a digital twin framework for real-time logistics simulation has been developed for SC coordination in modular construction. It can predict potential logistics risks and accurate arrival times [86].

As reported in [66] by key decision-makers in SC management, the need for an early warning system has been recognised to be extremely helpful to react, save costs for recovery, and set put recovery-management teams. The head of procurement of Merck also high- 
lighted the importance of having visibility to run analyses and react fast proactively [83]. Therefore, signal monitoring has been included in the roadmap's methodology.

\section{Discussion}

Uncertainty and unforeseeable disruptions can never be simply eliminated. Hence, preparedness and recovery are the responsibility of all SC entities, and close coordination is imperative to overcoming major disruptions. The detailed definition of plausible scenarios could help decision-makers deploy strategies to reduce impacts and support a return to normal operations.

The defined strategies could help improve SC resiliency, but they can also cause an increase in costs or the selection of less sustainable alternatives. For instance, the development of additional sourcing could increase SC capital investments and coordination costs. The proposed strategies could also define solutions such as transportation expediting and less-than-a-truck-loads that could be less sustainable alternatives and troublesome for the day-to-day operations. Therefore, during the analysis of scenarios, trade-offs need to be considered. While some companies are willing to invest in proactive strategies, not all companies can take a preventive approach due to resource limitations or lack of engagement from top management.

The roadmaps proposed in the present study show that there is no one-size-fits-all solution. Each SC needs a creative and customised process to develop roadmaps. Strategies presented in the food sector may not apply to the retail or healthcare sectors. Hence, appropriate preparations and adjustments need to be made. The proposed methodology for developing supply chain resilience roadmaps provides a baseline process to follow. Although each stage of the roadmaps is backed up with the existing literature and examples, they are not intended to be a step-by-step recipe.

The development of roadmaps enables a multi-method analysis in which decisionmakers could include brainstorming, red teaming, AFD, simulation, optimisation, and data-driven technologies like digital twins. However, other methodologies and theories can be adopted at each stage. For instance, Craighead et al. [5] proposed a toolbox containing 10 theories that could be used for understanding SC behaviour before, during, and after a pandemic.

As a unique contribution, the supply chain resilience roadmaps concentrate on the synergy of well-established methodologies to create a method to prepare for unexpected events. Additionally, each stage of the roadmaps opens directions for future development.

\section{Conclusions}

Although SC disruptions have attracted attention during the last decade, disruptive events characterised by low probability and high impact have received little attention. The lack of information has caused decision-makers to ignore them. However, as today's SCs are in a deeply interconnected global environment, underestimated events could be catastrophic and propagate to a different place from the initial disruption, increasing the risk of exacerbating a crisis.

While it is true that a perfect system or SC can never be designed-as surprises will always occur-knowing how systems behave and understanding the possible implications when facing major disruptions could help mitigate the impacts of any disruption.

We can no longer simply ignore situations because their probabilities are too low or not calculable. We must strive to create a broad range of plausible scenarios to analyse SCs. Scenarios are used as a tool for strategizing about uncertainties in an evolutionary SC environment. A scenario mindset could help us to evaluate and thus be better prepared for situations that could arise in the future.

In this study, we have proposed a methodology to develop supply chain resilience roadmaps, which are intended to describe scenarios that could drastically change the SC environment and propose guidelines to follow to decrease and mitigate the impacts of any disruption. We are not looking to create a plan for every imaginable scenario but to create 
a set of plausible futures. We want to improve the understanding of major disruptions in a system thinking environment. We want proactive planning for unexpected events to ensure system adaptation to internal and external threats.

As the process of developing the roadmaps can be lengthy, top-management support is crucial. Hence, understanding the need to develop the roadmaps should be made as clear as possible; however, the benefits of developing the scenarios are highly unlikely to become tangible in the short term.

Although the methodology for developing roadmaps has not been implemented in a case study, each stage of the roadmap methodology has been backed up with examples available in the literature. Moreover, the development of scenarios is justifiable as organisations have implemented them to develop business strategies and governments to tackle disruptions, such as major natural disasters, and now for predicting impacts of the current COVID-19 pandemic. While this research represents the initial steps towards a more aware SC preparedness, it establishes the foundations for a holistic SC disruption analysis.

Author Contributions: Conceptualization, J.O.-A. and A.V.-S.; methodology, J.O.-A. and A.V.-S.; J.O.-A. and A.V.-S.; investigation, J.O.-A. and A.V.-S.; writing-original draft preparation, J.O.-A. and A.V.-S.; writing-review and editing, J.O.-A. and A.V.-S.; visualization, J.O.-A. and A.V.-S.; funding acquisition, J.O.-A. and A.V.-S. All authors have read and agreed to the published version of the manuscript.

Funding: This research was partially funded by Cape Breton University, project numbers 4081046 and 4081156.

Institutional Review Board Statement: Not applicable.

Informed Consent Statement: Not applicable.

Data Availability Statement: Not applicable.

Conflicts of Interest: The authors declare no conflict of interest.

\section{References}

1. Pettit, T.J.; Croxton, K.L.; Fiksel, J. Ensuring Supply Chain Resilience: Development and Implementation of an Assessment Tool. J. Bus. Logist. 2013, 34, 46-76. [CrossRef]

2. Taleb, N.N. The Black Swan: The Impact of the Highly Improbable; Random House: New York, NY, USA, 2007 ; Volume 2.

3. Sodhi, M.S.; Tang, C.S.; Willenson, E.T. Research opportunities in preparing supply chains of essential goods for future pandemics. Int. J. Prod. Res. 2021, 1-16. [CrossRef]

4. Salama, M.R.; McGarvey, R.G. Resilient supply chain to a global pandemic. Int. J. Prod. Res. 2021, 1-31. [CrossRef]

5. Craighead, C.W.; Ketchen, D.J., Jr.; Darby, J.L. Pandemics and Supply Chain Management Research: Toward a Theoretical Toolbox. Decis. Sci. 2020, 51, 838-866. [CrossRef] [PubMed]

6. Ivanov, D.; Dolgui, A. Stress testing supply chains and creating viable ecosystems. Oper. Manag. Res. 2021, 1-12. [CrossRef]

7. Ho, W.; Zheng, T.; Yildiz, H.; Talluri, S. Supply chain risk management: A literature review. Int. J. Prod. Res. 2015, 53, 5031-5069. [CrossRef]

8. Sheffi, Y. Chapter 4-Modeling Risks in Supply Chains, in Finance and Risk Management for International Logistics and the Supply Chain; Gong, S., Cullinane, K., Eds.; Elsevier: Amsterdam, The Netherlands, 2018; pp. 55-84.

9. Xu, S.; Zhang, X.; Feng, L.; Yang, W. Disruption risks in supply chain management: A literature review based on bibliometric analysis. Int. J. Prod. Res. 2020, 58, 3508-3526. [CrossRef]

10. Sheffi, Y.; Rice, J.B., Jr. A supply chain view of the resilient enterprise. MIT Sloan Manag. Rev. 2005, 47, 41.

11. Dolgui, A.; Ivanov, D.; Sokolov, B. Reconfigurable supply chain: The X-network. Int. J. Prod. Res. 2020, 58, 4138-4163. [CrossRef]

12. Ivanov, D. Viable supply chain model: Integrating agility, resilience and sustainability perspectives-lessons from and thinking beyond the COVID-19 pandemic. Ann. Oper. Res. 2020, 1. [CrossRef]

13. Craighead, C.W.; Blackhurst, J.; Rungtusanatham, M.J.; Handfield, R.B. The Severity of Supply Chain Disruptions: Design Characteristics and Mitigation Capabilities. Decis. Sci. 2007, 38, 131-156. [CrossRef]

14. Kleindorfer, P.R.; Saads, G.H. Managing Disruption Risks in Supply Chains. Prod. Oper. Manag. 2005, 14, 53-68. [CrossRef]

15. Tang, C.S. Perspectives in supply chain risk management. Int. J. Prod. Econ. 2006, 103, 451-488. [CrossRef]

16. Sornette, D. Dragon-kings, black swans and the prediction of crises. arXiv 2009, arXiv:0907.4290. [CrossRef]

17. Paté-Cornell, E. On "Black Swans" and "Perfect Storms": Risk Analysis and Management When Statistics Are Not Enough. Risk Anal. 2012, 32, 1823-1833. [CrossRef]

18. Klibi, W.; Martel, A. Scenario-based Supply Chain Network risk modeling. Eur. J. Oper. Res. 2012, 223, 644-658. [CrossRef] 
19. Aven, T. On the meaning of a black swan in a risk context. Saf. Sci. 2013, 57, 44-51. [CrossRef]

20. Akkermans, H.; Van Wassenhove, L.N. Supply Chain Tsunamis: Research on Low-Probability, High-Impact Disruptions. J. Supply Chain. Manag. 2018, 54, 64-76. [CrossRef]

21. Van Eck, N.J.; Waltman, L. VOSviewer Manual. 2020. Available online: https://www.vosviewer.com/documentation/Manual_ VOSviewer_1.6.17.pdf (accessed on 14 January 2021).

22. Aven, T. Aven, T. A conceptual foundation for assessing and managing risk, surprises and black swans. In The Illusion of Risk Control; Motet, G., Bieder, C., Eds.; Springer: Cham, Switzerland, 2017; pp. 23-39.

23. Ivanov, D.; Dolgui, A.; Sokolov, B.; Ivanova, M. Literature review on disruption recovery in the supply chain. Int. J. Prod. Res. 2017, 55, 6158-6174. [CrossRef]

24. Christopher, M.; Peck, H. Building the Resilient Supply Chain. Int. J. Logist. Manag. 2004, 15, 1-13. [CrossRef]

25. Knemeyer, A.M.; Zinn, W.; Eroglu, C. Proactive planning for catastrophic events in supply chains. J. Oper. Manag. 2009, 27, 141-153. [CrossRef]

26. Sodhi, M.S.; Tang, C.S. Managing Supply Chain Disruptions via Time-Based Risk Management. In Managing Supply Chain Risk and Vulnerability: Tools and Methods for Supply Chain Decision Makers; Wu, T., Blackhurst, J., Eds.; Springer: London, UK, 2009; pp. 29-40.

27. Pettit, T.J.; Fiksel, J.; Croxton, K.L. Ensuring supply chain resilience: Development of a conceptual framework. J. Bus. Logist. 2010, 31, 1-21. [CrossRef]

28. Blackhurst, J.; Dunn, K.S.; Craighead, C.W. An Empirically Derived Framework of Global Supply Resiliency. J. Bus. Logist. 2011, 32, 374-391. [CrossRef]

29. Ghadge, A.; Dani, S.; Chester, M.; Kalawsky, R. A systems approach for modelling supply chain risks. Supply Chain. Manag. Int. J. 2013, 18, 523-538. [CrossRef]

30. Bradley, J.R. An improved method for managing catastrophic supply chain disruptions. Bus. Horiz. 2014, 57, 483-495. [CrossRef]

31. Simchi-Levi, D.; Schmidt, W.; Wei, Y.; Zhang, P.Y.; Combs, K.; Ge, Y.; Gusikhin, O.; Sanders, M.; Zhang, D. Identifying Risks and Mitigating Disruptions in the Automotive Supply Chain. Interfaces 2015, 45, 375-390. [CrossRef]

32. Thekdi, S.A.; Santos, J.R. Supply Chain Vulnerability Analysis Using Scenario-Based Input-Output Modeling: Application to Port Operations. Risk Anal. 2016, 36, 1025-1039. [CrossRef]

33. Pavlov, A.; Ivanov, D.; Werner, F.; Dolgui, A.; Sokolov, B. Integrated detection of disruption scenarios, the ripple effect dispersal and recovery paths in supply chains. Ann. Oper. Res. 2019, 1-23. [CrossRef]

34. Ivanov, D.; Dolgui, A. Low-Certainty-Need (LCN) supply chains: A new perspective in managing disruption risks and resilience. Int. J. Prod. Res. 2018, 57, 5119-5136. [CrossRef]

35. Adobor, H. Supply chain resilience: A multi-level framework. Int. J. Logist. Res. Appl. 2019, 22, 533-556. [CrossRef]

36. Olivares-Aguila, J.; ElMaraghy, W. System dynamics modelling for supply chain disruptions. Int. J. Prod. Res. 2020, 59, 1757-1775. [CrossRef]

37. Schätter, F.; Hansen, O.; Wiens, M.; Schultmann, F. A decision support methodology for a disaster-caused business continuity management. Decis. Support Syst. 2019, 118, 10-20. [CrossRef]

38. Ivanov, D. Predicting the impacts of epidemic outbreaks on global supply chains: A simulation-based analysis on the coronavirus outbreak (COVID-19/SARS-CoV-2) case. Transp. Res. Part E Logist. Transp. Rev. 2020, 136, 101922. [CrossRef]

39. Bier, T.; Lange, A.; Glock, C.H. Methods for mitigating disruptions in complex supply chain structures: A systematic literature review. Int. J. Prod. Res. 2020, 58, 1835-1856. [CrossRef]

40. Olivares-Aguila, J.; Elmaraghy, W. Structural complexity and robustness of supply chain networks based on product architecture. Int. J. Prod. Res. 2018, 56, 6701-6718. [CrossRef]

41. Aven, T. Implications of black swans to the foundations and practice of risk assessment and management. Reliab. Eng. Syst. Saf. 2015, 134, 83-91. [CrossRef]

42. Kaplan, S.; Visnepolschi, S.; Zlotin, B.; Zusman, A. New Tools for Failure and Risk Analysis: An Introduction to Anticipatory Failure Determination (Afd) and the Theory of Scenario Structuring; Ideation International: Farmington Hills, MI, USA, 1999.

43. Masys, A.J. Black swans to grey swans: Revealing the uncertainty. Disaster Prev. Manag. Int. J. 2012, 21, 320-335. [CrossRef]

44. Varum, C.A.; Melo, C. Directions in scenario planning literature-A review of the past decades. Futures 2010, 42, 355-369. [CrossRef]

45. Wack, P. Scenarios: Shooting the Rapids. Harv. Bus. Rev. 1985, 6, 139-150.

46. Schoemaker, P.J. Scenario planning: A tool for strategic thinking. Sloan Manag. Rev. 1995, 36, 25-50.

47. Strong, K.; Carpenter, O.; Ralph, D. Scenario Best Practices: Developing Scenarios for Disaster Risk Reduction; Cambridge Centre for Risk Studies at the University of Cambridge Judge Business School and Lighthill Risk Network: Cambridge, UK, 2020.

48. Van der Heijden, K. Scenarios: The Art of Strategic Conversation; John Wiley \& Sons: West Sussex, UK, 2011.

49. Sodhi, M.S. How to do strategic supply-chain planning. Sloan Manag. Rev. 2003, 45, 69-75.

50. Thomas, C.; Chermack, T. Using Scenario Planning to Supplement Supply Chain Risk Assessments, Revisiting Supply Chain Risk; Springer: Berlin, Germany, 2019.

51. Simchi-Levi, D.; Simchi-Levi, E. We Need a Stress Test for Critical Supply Chains. Harv. Bus. Rev. 2020. Available online: https:/ /hbr-org.cdn.ampproject.org/c/s/hbr.org/amp/2020/04/we-need-a-stress-test-for-critical-supply-chains (accessed on 9 January 2021). 
52. Comes, T.; Bertsch, V.; French, S. Designing dynamic stress tests for improved critical infrastructure resilience. ISCRAM 2013, 307-311. Available online: http:/ /idl.iscram.org/files/comes/2013/405_Comes_etal2013.pdf (accessed on 9 January 2021).

53. Sheffi, Y. The Power of Resilience: How the Best Companies Manage the Unexpected; MIT Press: Cambridge, MA, UK, 2015.

54. Golan, M.S.; Jernegan, L.H.; Linkov, I. Trends and applications of resilience analytics in supply chain modeling: Systematic literature review in the context of the COVID-19 pandemic. Environ. Syst. Decis. 2020, 40, 222-243. [CrossRef]

55. Peng, T.; He, Q.; Zhang, Z.; Wang, B.; Xu, X. Industrial Internet-enabled Resilient Manufacturing Strategy in the Wake of COVID-19 Pandemic: A Conceptual Framework and Implementations in China. Chin. J. Mech. Eng. 2021, 34, 48. [CrossRef]

56. Ivanov, D. Supply Chain Viability and the COVID-19 pandemic: A conceptual and formal generalisation of four major adaptation strategies. Int. J. Prod. Res. 2021, 59, 3535-3552. [CrossRef]

57. Barroso, A.P.; Machado, V.H.; Machado, V.C. Supply chain resilience using the mapping approach. Supply Chain. Manag. 2011, 161-184. Available online: http://www.intechopen.com/books/supply-chain-management/supply-chain-resilience-usingthemapping-approach (accessed on 14 April 2021).

58. Gusikhin, O.; Klampfl, E. JEDI: Just-in-time execution and distribution information support system for automotive stamping operations. In Decision Policies for Production Networks; Springer: London, UK, 2012; pp. 119-142.

59. Mubarik, M.S.; Naghavi, N.; Mubarik, M.; Kusi-Sarpong, S.; Khan, S.A.; Zaman, S.I.; Kazmi, S.H. Resilience and cleaner production in industry 4.0: Role of supply chain mapping and visibility. J. Clean. Prod. 2021, 292, 126058. [CrossRef]

60. Bunn, D.W.; Salo, A.A. Forecasting with scenarios. Eur. J. Oper. Res. 1993, 68, 291-303. [CrossRef]

61. Ivanov, D.; Dolgui, A. A digital supply chain twin for managing the disruption risks and resilience in the era of Industry 4.0. Prod. Plan. Control. 2020, 32, 775-788. [CrossRef]

62. Ivanov, D.; Dolgui, A.; Das, A.; Sokolov, B. Digital Supply Chain Twins: Managing the Ripple Effect, Resilience, and Disruption Risks by Data-Driven Optimization, Simulation, and Visibility. In Handbook of Ripple Effects in the Supply Chain; Ivanov, D., Dolgui, A., Sokolov, B., Eds.; Springer International Publishing: Cham, Switzerland, 2019; pp. 309-332.

63. Chermack, T.J. Scenario Planning in Organizations: How to Create, Use, and Assess Scenarios; Berrett-Koehler Publishers: San Francisco, CA, USA, 2011.

64. Noori, N.S.; Wang, Y.; Comes, T.; Schwarz, P.; Lukosch, H.K. Behind the Scenes of Scenario-Based Training: Understanding Scenario Design and Requirements in High-Risk and Uncertain Environments. ISCRAM 2017, 948-959. Available online: http:/ / pure.tudelft.nl/ws / files/33894456/iscram2017_iTRACKScenarios.pdf (accessed on 14 August 2021).

65. Coburn, A.; Ralph, D.; Tuveson, M.; Ruffle, S.; Bowman, G. A Taxonomy of Threats for Macro-Catastrophe Risk Management; Working Paper; Centre for Risk Studies, University of Cambridge: Cambridge, UK, July 2013; pp. 20-24.

66. Ivanov, D. Digital Supply Chain Management and Technology to Enhance Resilience by Building and Using End-to-End Visibility During the COVID-19 Pandemic. IEEE Trans. Eng. Manag. 2021, 1-11. [CrossRef]

67. Johnson and Johnson. What You Need to Know about How Johnson \& Johnson's Supply Chain Is Responding to the COVID19 Pandemic. 2020. Available online: https://www.jnj.com/innovation/johnson-johnson-supply-chain-technology-duringcoronavirus (accessed on 24 September 2021).

68. Sheffi, Y. Preparing for disruptions through early detection. MIT Sloan Manag. Rev. 2015, 57, 31.

69. Ivanov, D.; Dolgui, A. OR-methods for coping with the ripple effect in supply chains during COVID-19 pandemic: Managerial insights and research implications. Int. J. Prod. Econ. 2021, 232, 107921. [CrossRef]

70. Wilson, M.C. The impact of transportation disruptions on supply chain performance. Transp. Res. Part E Logist. Transp. Rev. 2007, 43, 295-320. [CrossRef]

71. Carvalho, H.; Barroso, A.P.; Machado, V.; Azevedo, S. Supply chain redesign for resilience using simulation. Comput. Ind. Eng. 2012, 62, 329-341. [CrossRef]

72. Schmitt, T.G.; Kumar, S.; Stecke, K.E.; Glover, F.W.; Ehlen, M.A. Mitigating disruptions in a multi-echelon supply chain using adaptive ordering. Omega 2017, 68, 185-198. [CrossRef]

73. Sterman, J.D. Business Dynamics: Systems Thinking and Modeling for a Complex World; McGraw-Hill Education: New York, NY, USA, 2000.

74. Zhu, Q.; Krikke, H. Managing a Sustainable and Resilient Perishable Food Supply Chain (PFSC) after an Outbreak. Sustainability 2020, 12, 5004. [CrossRef]

75. Zhu, Q.; Krikke, H.; Caniëls, M. The Effects of Different Supply Chain Integration Strategies on Disruption Recovery: A System Dynamics Study on the Cheese Industry. Logistics 2021, 5, 19. [CrossRef]

76. Sun, L.; Niu, D.; Wang, K.; Xu, X. Sustainable development pathways of hydropower in China: Interdisciplinary qualitative analysis and scenario-based system dynamics quantitative modeling. J. Clean. Prod. 2021, 287, 125528. [CrossRef]

77. Tordecilla, R.D.; Juan, A.A.; Montoya-Torres, J.R.; Quintero-Araujo, C.L.; Panadero, J. Simulation-optimization methods for designing and assessing resilient supply chain networks under uncertainty scenarios: A review. Simul. Model. Pract. Theory 2021, 106, 102166. [CrossRef]

78. Olivares-Aguila, J.; Elmaraghy, W.; Elmaraghy, H. Impact of risk attitudes on the concurrent design of supply chains and product architectures. Procedia CIRP 2019, 81, 974-979. [CrossRef]

79. Aguila, J.O.; ElMaraghy, W. Simultaneous global supply chain and product architecture design considering natural hazard exposure and geographical facility location. Procedia CIRP 2018, 72, 533-538. [CrossRef] 
80. He, J.; Alavifard, F.; Ivanov, D.; Jahani, H. A real-option approach to mitigate disruption risk in the supply chain. Omega 2019, 88, 133-149. [CrossRef]

81. Sheffi, Y. The New (Ab) Normal: Reshaping Business and Supply Chain Strategy Beyond Covid-19; MIT CTL Media: Cambridge, MA, USA, 2020.

82. Banker, S. A Very Agile Supply Chain: The Inside Story of AGCO's Response to COVID-19. 2020. Available online: https:/ / www.forbes.com/sites/stevebanker/2020/04/15/a-very-agile-supply-chain-the-inside-story-of-agcos-response-tocovid-19/?sh=2ca70548574d (accessed on 23 September 2021).

83. World Economic Forum. How to Rebound Stronger from COVID-19 Resilience in Manufacturing and Supply Systems. 2020. Available online: https:/ / www.weforum.org/whitepapers/how-to-rebound-stronger-from-covid-19-resilience-in-manufacturingand-supply-systems (accessed on 10 March 2021).

84. Schoemaker, P.J.; Day, G.S.; Snyder, S.A. Integrating organizational networks, weak signals, strategic radars and scenario planning. Technol. Forecast. Soc. Chang. 2013, 80, 815-824. [CrossRef]

85. Burgos, D.; Ivanov, D. Food retail supply chain resilience and the COVID-19 pandemic: A digital twin-based impact analysis and improvement directions. Transp. Res. Part E Logist. Transp. Rev. 2021, 152, 102412. [CrossRef]

86. Lee, D.; Lee, S. Digital Twin for Supply Chain Coordination in Modular Construction. Appl. Sci. 2021, 11, 5909. [CrossRef] 